\title{
Active zone proteins are dynamically associated with synaptic ribbons in rat pinealocytes
}

\author{
Isabella Spiwoks-Becker • Christian Maus • \\ Susanne tom Dieck • Anna Fejtová • Lydia Engel • \\ Tanja Wolloscheck • Uwe Wolfrum • Lutz Vollrath • \\ Rainer Spessert
}

Received: 7 November 2007 / Accepted: 18 April 2008/Published online: 4 June 2008

(C) Springer-Verlag 2008

\begin{abstract}
Synaptic ribbons (SRs) are prominent organelles that are abundant in the ribbon synapses of sensory neurons where they represent a specialization of the cytomatrix at the active zone (CAZ). SRs occur not only in neurons, but also in neuroendocrine pinealocytes where their function is still obscure. In this study, we report that pinealocyte SRs are associated with $\mathrm{CAZ}$ proteins such as Bassoon, Piccolo, CtBP1, Munc13-1, and the motorprotein KIF3A and, therefore, consist of a protein complex that resembles the ribbon complex of retinal and other sensory ribbon
\end{abstract}

Susanne tom Dieck was supported by DFG grant BR 1643/4-1, and Anna Fejtová by the European Commission (SynScaff).

I. Spiwoks-Becker $(\bowtie) \cdot$ C. Maus $\cdot$ L. Engel · T. Wolloscheck ·

L. Vollrath $\cdot$ R. Spessert

Department of Anatomy and Cell Biology,

Johannes Gutenberg University,

Becherweg 13,

55128 Mainz, Germany

e-mail: spiwoks@uni-mainz.de

\section{U. Wolfrum}

Insitute of Zoology, Department of Cell and Matrix Biology, Johannes Gutenberg University,

55128 Mainz, Germany

S. tom Dieck

Department of Neuroanatomy,

Max Planck Institute for Brain Research,

60528 Frankfurt/M, Germany

S. tom Dieck

Institute for Biology, Department of Animal Physiology,

University of Erlangen-Nürnberg,

91058 Erlangen, Germany

\section{A. Fejtová}

Department of Neurochemistry and Molecular Biology,

Leibniz Institute for Neurobiology,

39118 Magdeburg, Germany synapses. The pinealocyte ribbon complex is biochemically dynamic. Its protein composition changes in favor of Bassoon, Piccolo, and Munc13-1 at night and in favor of KIF3A during the day, whereas CtBP1 is equally present during the night and day. The diurnal dynamics of the ribbon complex persist under constant darkness and decrease after stimulus deprivation of the pineal gland by constant light. Our findings indicate that neuroendocrine pinealocytes possess a protein complex that resembles the CAZ of ribbon synapses in sensory organs and whose dynamics are under circadian regulation.

Keywords Cytomatrix at the active zone - RIBEYE . Ribbon synapse · Circadian system · Rat (Sprague Dawley)

\section{Introduction}

Synaptic ribbons (SRs) are electron-dense structures capable of tethering numerous synaptic vesicles by tiny stalks (Rao-Mirotznik et al. 1995). In mammals, SRs occur in sensory cells of the retina and inner ear (for reviews, see Vollrath and Spiwoks-Becker 1996; Lenzi and von Gersdorff 2001; Nouvian et al. 2006) and in pinealocytes, the parenchymal cells of the pineal gland (for reviews, see Bhatnagar 1994; McNulty and Fox 1992; Vollrath and Spiwoks-Becker 2002). SRs are the morphological hallmark of a unique type of chemical synapse, referred to as a ribbon synapse (for reviews, see Morgans 2000; Sterling and Matthews 2005; tom Dieck and Brandstätter 2006). In photoreceptor cells, the majority of SRs appear as rod-like structures in ultrathin sections, whereas in three dimensions, they are thin plates with a horseshoe-like shape measuring $30-50 \mathrm{~nm}$ in width and up to $2 \mu \mathrm{m}$ in length. SRs are highly dynamic and undergo reversible light-dependent morpholog- 
ical changes within minutes (Spiwoks-Becker et al. 2004). The putative role of the SRs in photoreceptor function is the tonic release of neurotransmitter by providing a pool of vesicles for synaptic release and/or by acting as a conveyer belt to transport vesicles to the presynaptic membrane.

A major component of the SRs is RIBEYE (Schmitz et al. 2000), the only known protein specific to SRs. Surprisingly, RIBEYE is derived from the gene coding for the transcriptional co-repressor $\mathrm{CtBP} 2(\mathrm{COOH}-t e r m i n a l$ binding protein 2) by use of an alternative promotor (Schmitz et al. 2000). Thus, RIBEYE consists of a ribbon-specific A-domain (RIBEYE A) and a B-domain (RIBEYE B) that is identical to CtBP2, except for the first 20 amino acids. Other molecular components enriched at photoreceptor SRs are the kinesin motor protein KIF3A (Muresan et al. 1999) and a variety of proteins of the CAZ (cytomatrix at the active zone) known from conventional active zones. This has led to the assumption that SRs are a specialization of the CAZ present at conventional synapses (Dresbach et al. 2001). The ribbon complex of photoreceptor cells can be segregated into a ribbon-associated compartment harboring Bassoon, Piccolo, RIM1, CtBP1, and KIF3A, and an active zone compartment including RIM2, Munc13-1, and ERC/CAST (tom Dieck et al. 2005). Progress has been made in the characterization of these synaptic proteins (Zhai and Bellen 2004), but little is known about their specific functions. An exception is Bassoon which plays an important role in anchoring SRs at the CAZ (Dick et al. 2003). As the release of transmitter from the ribbon synapse in Bassoon mutant mice is perturbed (Dick et al. 2003), the Bassoon-mediated association of the SR with the proteins of the CAZ appears to be a prerequisite for proper synaptic function.

In the pinealocytes of mammals, SRs are basically flat plate-like structures. In the pineal organ of rats, they exhibit a thickness of 30-40 nm, a mean length of $200 \mathrm{~nm}$, and a maximal dimension of $800 \mathrm{~nm}$ (Jastrow et al. 1997). They are often, but not exclusively, localized in the immediate vicinity of the plasmalemma (Vollrath 1981). The protein composition of the pinealocyte SR is unknown. Since rat pinealocytes show RIBEYE B immunoreactivity (Schmitz et al. 2000), pinealocyte SRs are probably also composed of RIBEYE. As seen in rod photoreceptor cells, mammalian pineal SRs exhibit diurnal plasticity. Their profile number is higher at night than during the day (Vollrath 1973; Jastrow et al. 1997); this may result from an increase in the size and/or number of SRs (Jastrow et al. 1997). SRs of the mammalian pineal gland have been proposed to be non-functional, representing phylogenetic relics of the original neurosensory function of pinealocytes (Bhatnagar 1994). However, the localization of SRs near the cell membrane, their topographical relationship to neighboring pinealocytes, and their characteristic morphological changes under various condi- tions support an involvement of pineal SRs in transmitter release and intercellular communication (Vollrath 1981; McNulty and Fox 1992; Vollrath and Spiwoks-Becker 2002).

Here, we provide evidence that CAZ proteins involved in synaptic transmission are dynamically associated with pinealocyte SRs. Since these proteins seem to be a prerequisite for vesicle release, we conclude that pinealocyte SRs are indeed functionally involved in transmitter release and contribute to cell signaling.

\section{Materials and methods}

Animals

Animal experimentation was carried out in accordance with the European Communities Council Directive (86/609/ EEC). Adult male and female Sprague-Dawley rats (body weights: $150-180 \mathrm{~g}$ ) were kept for 3 weeks under standard laboratory conditions (illumination with fluorescent strip lights, 200 lux at cage level during the day and dim red light during the night; $20 \pm 1^{\circ} \mathrm{C}$; water and food ad libitum) with a light/dark regime (LD) of 12:12. When indicated, the rats were then kept for two cycles under dim red light or constant light and killed during the next cycle. Animals were killed at the indicated time-points by decapitation under open ether anesthesia. During the dark phase, dissections were carried out under dim red light. The pineal glands and retinae were gently removed and processed for postembedding immunoelectron microscopy, immunohistochemistry or Western blot. For RNA extraction, the organs were immediately frozen in liquid $\mathrm{N}_{2}$ and kept at $-70^{\circ} \mathrm{C}$.

\section{Antibodies}

The following primary antibodies were used: rabbit antiBassoon polyclonal antibody (pAb; immunohistochemistry [IHC] 1:200; Synaptic Systems, Göttingen, Germany), mouse anti-CtBP1 monoclonal antibody (mAb; IHC 1:1,000), anti-RIBEYE B/CtBP2 mAbs (postembedding immunoelectron microscopy [post-EM] 1:1,000; IHC 1:1,000; BD Biosciences, Franklin Lakes, N.J., USA), rabbit anti-ERC1b/2 pAb (also known as CAST; IHC 1:500; Synaptic Systems), mouse anti-kinesin II mAb (IHC 1:50; COVANCE/BabCO, Richmond, Calif., USA), rabbit anti-Munc13-1 pAb (IHC 1:500; Synaptic Systems), rabbit anti-Piccolo4 $\mathrm{pAb}$ (raised against a fusion protein with glutathione S-transferase against amino acids 59-250 of rat Piccolo; IHC 1:2,000), rabbit anti-RIBEYE A pAb (amino acids 179-448; IHC 1:2,000-1:4,000; post-EM 1:1,000; see tom Dieck et al. 2005), rabbit anti-RIM1 (IHC 1:200), or antiRIM2 pAbs (IHC 1:200; Synaptic Systems). The binding sites of the primary antisera were revealed by secondary antisera, 
viz., goat anti-rabbit IgG coupled to Alexa 488 (green fluorescence) or goat anti-mouse IgG coupled to Alexa 594 (red fluorescence; both diluted 1:500; Molecular Probes, Eugene, Ore., USA). The latter secondary antibody (Alexa 594; anti-mouse) cross-reacted with pineal blood vessels, but in general, the structures of interest (e.g., pinealocytes with their nuclei and SRs) were easily distinguishable. However, the superior dye properties of the Alexa antibodies, including brightness and linear and non-fading fluorescence signals, gave a higher signal correlation and, thus, higher confidence in determining significant differences in protein expression.

\section{Postembedding immunoelectron microscopy}

Fixation, embedding, and further handling of rat retinal and pineal samples for immunoelectron microscopy were performed according to Wolfrum and Schmitt (2000), nanogold labeling being silver-enhanced (Danscher 1981). Counterstained ultrathin sections were analyzed with a LEO transmission electron microscope (TEM) 906E (Zeiss, Oberkochen, Germany).

\section{Immunofluorescence microscopy}

The isolated pineal glands and retinae were immersion fixed in $4 \%(\mathrm{w} / \mathrm{v})$ paraformaldehyde in phosphate buffer $(\mathrm{PB} ; 0.1 \mathrm{M}$, $\mathrm{pH}$ 7.4) for 15-30 min. The fixed tissue was washed in $\mathrm{PB}$ and then cryoprotected by sequential immersion in $10 \%, 20 \%$, and $30 \%(\mathrm{w} / \mathrm{v})$ sucrose in PB. Sections were cut at a thickness of $8 \mu \mathrm{m}$ (pineal gland) or $8-10 \mu \mathrm{m}$ (retina) on a cryostat and mounted onto Super-Frost glass slides. The slides were airdried and stored at $-20^{\circ} \mathrm{C}$. Immunocytochemical labeling was performed by the indirect fluorescence method according to Dick et al. (2001, 2003). Negative controls were performed by omitting the primary antibody. Confocal images were recorded with a laser-scanning microscope (model TCS SP2, Leica Microsystems, Heidelberg, Germany). Multiple pairs of optical sections were recorded at different depths throughout the tissue sections and merged into a single plane (Image-Pro Plus 5.0, Media Cybernetics, Silver Spring, Md., USA). Photoshop software (Adobe Photoshop 7.01, Adobe Systems, San Jose, Calif., USA) was used to edit single pictures and to assemble figures. For analysis by immunofluorescence microscopy, each experimental treatment was carried out independently four times, with two or three animals being studied in each experiment.

\section{Western blot}

For Western blot analysis, tissues were homogenized in the presence of protease inhibitors. To reduce volume, total protein of the homogenates was precipitated with an equal volume of $20 \%$ trichloroacetic acid. After an acetone wash, the precipitate was dissolved in $1.5 \times$ NuPAGE LDS sample buffer (Invitrogen, Carlsbad, Calif.), boiled (5 min), and treated with $0.2 \%$ iodoacetamide (Sigma, St. Louis, Mo.). Samples corresponding to $15 \mu \mathrm{g}$ or $25 \mu \mathrm{g}$ total protein were loaded on $3 \%-8 \%$ NuPAGE Novex TRIS-acetate gels (Invitrogen), separated, and blotted onto polyvinylidene difluoride membranes (Westran Clear signal, Schleicher \& Schüll, Dassel, Germany). Blots were stained with Ponceau $\mathrm{S}$ (Sigma) to control for equal loading. For immunodetection, membranes were blocked, and the primary antibody was applied overnight at $4^{\circ} \mathrm{C}$. The horseradish-peroxidasecoupled secondary antibodies (goat anti-mouse-HRP 1:30,000 [Sigma]; goat anti-rabbit-HRP 1:30,000 [New England Biolabs, Ipswich, Mass.]; goat anti-guineapig-HRP 1:20,000 [Dianova, Hamburg, Germany]) were visualized by an enhanced chemiluminescence detection system (Amersham Biosciences, Freiburg, Germany). Light-dark blots were probed subsequently with different primary antibodies (guinea-pig anti-Piccolo44a 1:4,000 [Dick et al. 2001]; rabbit anti-Bassoon sap7f 1:5,000 [tom Dieck et al. 1998]; rabbit anti-munc13 1:1,000 [Synaptic Systems]); mouse anti-RIBEYE/CtBP2 1:5,000; mouse anti-kinesin II/KIF3a 1:2,000). In total, four blots were analyzed, each containing samples from all animals.

\section{RNA isolation}

The RNA of three pooled pineal glands was isolated by using the RNeasy Mini Kit (Qiagen, Hilden, Germany) following the instructions of the manufacturer. The amount of extracted RNA was determined by measurement of the optical density at 260 and $280 \mathrm{~nm}$.

\section{Reverse transcription}

Extracted RNA $(1 \mu \mathrm{g})$ was reverse-transcribed by using $4 \mathrm{U}$ Omniscript reverse-transcriptase (Qiagen) in a total volume of $20 \mu \mathrm{l}$, containing $2.0 \mu \mathrm{l} 10$-fold buffer (supplied with the transcriptase), $0.4 \mu \mathrm{l}$ each deoxynucleotide triphosphate $(25 \mu \mathrm{M}), 20 \mathrm{U}$ ribonuclease inhibitor (Ambion, Huntingdon, UK), and $2 \mu \mathrm{l}$ oligo(dT) primer $(10 \mu \mathrm{M}$; MWG Biotech, Ebersberg, Germany). A sample without added RNA was routinely included as a negative control. The reverse transcription (RT) mixture was incubated at $37^{\circ} \mathrm{C}$ for $60 \mathrm{~min}$ to promote cDNA synthesis. The reaction was terminated by heating the sample at $95^{\circ} \mathrm{C}$ for $5 \mathrm{~min}$. cDNA was diluted 1:5 or 1:25 in RNAse-free distilled water, and aliquots of $5 \mu \mathrm{l}$ were used for polymerase chain reactions (PCR).

\section{Real-time PCR}

Real-time PCR was carried out in a total volume of $25 \mu \mathrm{l}$ containing $12.5 \mu \mathrm{l}$ Absolute TMSYBR Green Fluorescein 
mix (Abgene, Hamburg, Germany), $0.75 \mu 1$ primer (10 $\mathrm{mM}$ ) each, $6 \mu \mathrm{l}$ sterilized water (Roth, Karlsruhe, Germany), and $5 \mu$ sample. The primer sequences are listed in Table 1. PCR amplification and quantification were performed in an i-Cycler (BioRad, Munich, Germany) as follows: denaturation for $3 \mathrm{~min}$ at $95^{\circ} \mathrm{C}$, followed by 40 cycles of $50 \mathrm{~s}$ at $95^{\circ} \mathrm{C}, 20 \mathrm{~s}$ at $60^{\circ} \mathrm{C}$, and $20 \mathrm{~s}$ at $72^{\circ} \mathrm{C}$. All amplifications were carried out in duplicate. The amount of RNA was calculated from the measured threshold cycles by a standard curve. The data were normalized by determination of the amount of rat glyceraldehyde-3-phosphate dehydrogenase (Genbank accession number: NM_017008).

Statistical analysis

All PCR data are given as the mean \pm SEM of three independent experiments $(n=3$; each derived from two or three pooled pineal glands). The oscillation of expression of each transcript was analyzed by using an one-way analysis of variance (ANOVA).

\section{Results}

Staining for RIBEYE and CtBP2 in rat pineal gland

We assessed the expression of RIBEYE in the pineal organ on immunoblots with the B-domain-specific RIBEYE antibody (Fig. 1). As expected, we found two protein bands of $\sim 110 \mathrm{kDa}$ and $120 \mathrm{kDa}$ characteristic for RIBEYE (tom Dieck et al. 2005), both in the retina and in the pineal gland (Fig. 1). To investigate whether RIBEYE was specifically localized at pinealocyte SRs, postembedding immunogold electron microscopy was performed with antibodies against the A- and B-domains of RIBEYE. Both

Table 1 Primer sequences used ( $A A-N A T$ arylalkylamine Nacetyltransferase)

\begin{tabular}{|c|c|c|c|}
\hline \multirow{3}{*}{$\begin{array}{l}\text { Gene } \\
A A-N A T\end{array}$} & \multirow{3}{*}{$\begin{array}{l}\begin{array}{l}\text { Accession } \\
\text { number }\end{array} \\
\text { U40803 }\end{array}$} & \multicolumn{2}{|c|}{ Primer sequence $5^{\prime}$ to $3^{\prime}$} \\
\hline & & Forward & GAAGGGAGACAGCAGTTC \\
\hline & & Reverse & GTCCTGGTCTTGCCTTTG \\
\hline \multirow[t]{2}{*}{ RIBEYE } & AF222712 & Forward & AGGTCGCATTCCAGAAAG \\
\hline & & Reverse & CTGTATGTGGCACCATTGAG \\
\hline \multirow[t]{2}{*}{ Bassoon } & NM_019146 & Forward & CCCAGCTCTGCTGATTACTC \\
\hline & & Reverse & TGGCTGCAGTACAGTAGG \\
\hline \multirow[t]{2}{*}{ Piccolo } & NM_020098 & Forward & СТGCCTCTCACCCAATTACAG \\
\hline & & Reverse & ACAAACGGGTCAGAGTAGC \\
\hline \multirow[t]{2}{*}{ Munc13-1 } & NM_022861 & Forward & CACAGGACGCAGACAAC \\
\hline & & Reverse & AGCACCCGCTTCAGAAC \\
\hline \multirow[t]{2}{*}{ KIF3A } & XM_340796 & Forward & CTCTGCTTCGCCAGTTTC \\
\hline & & Reverse & ACCCTCCTCGTTGTCATC \\
\hline
\end{tabular}

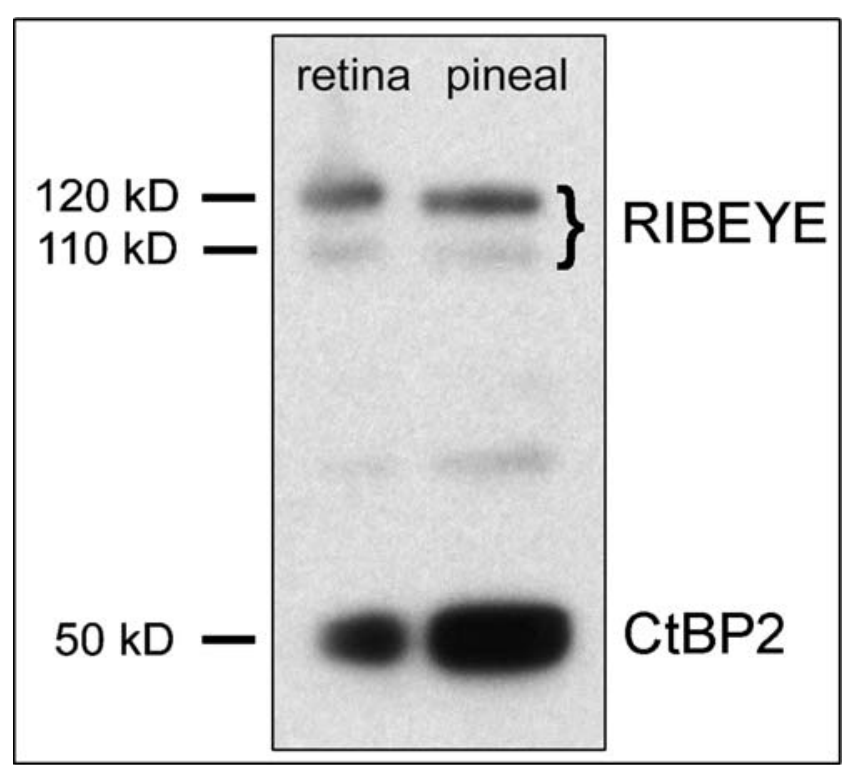

Fig. 1 Western blot analysis of RIBEYE expression in rat retina and pineal organ. The anti-B-domain RIBEYE antibody recognizes the RIBEYE doublet of $\sim 110 \mathrm{kDa}$ and $120 \mathrm{kDa}$ characterized in mouse retina (see tom Dieck et al. 2005) in pineal homogenate (right lane) and in rat retina (left lane). The $50-\mathrm{kDa}$ protein band represents the transcriptional corepressor CtBP2. Equivalent amounts of retinal and pineal sample $(25 \mu \mathrm{g}$ of total protein) were loaded into each lane

antibodies clearly labeled SRs in photoreceptor terminals (Fig. 2a,c) and pinealocytes (Fig. 2b,d). Immunolabeling was confined to the electron-dense matrix of the SRs. Confocal laser-scanning images (Figs. 2e-h, 3a,b) revealed that the same SR was stained by both antibodies. Closer examination of the immunostained preparations showed that SRs of pinealocytes and rod photoreceptor cells exhibited striking differences in shape and RIBEYE staining. Pinealocyte SRs appeared as punctate or short (150-200 nm long), rod-like, evenly stained structures, lying relatively wide apart (Fig. 2f,h). Photoreceptor SRs were much larger (up to $2 \mu \mathrm{m}$ ) than pinealocyte SRs and lay more closely together. They were bent to variable degrees, resembling horseshoes, and exhibited particularly strong staining at their ends (Fig. 2e,g).

RIBEYE B/CtBP2 antibodies (Figs. 3a,b, 4a-f, 6), but not RIBEYE A antibodies (Figs. 3c,d, 4g,h), also stained the cell nuclei in the pineal gland. The immunoreactivity in the nuclei represented the 50-kDa CtBP2 transcriptional corepressor, correlating with the demonstrated large amount of CtBP2 protein in Western blot analysis (Fig. 1). Hence, our study shows that both RIBEYE and CtBP2 are transcribed from the RIBEYE/CtBP2 gene in rat pinealocytes.

SR-associated CAZ proteins in rat pineal gland

A main aim of the present study was to examine whether CAZ proteins found at photoreceptor SRs (Muresan et al. 


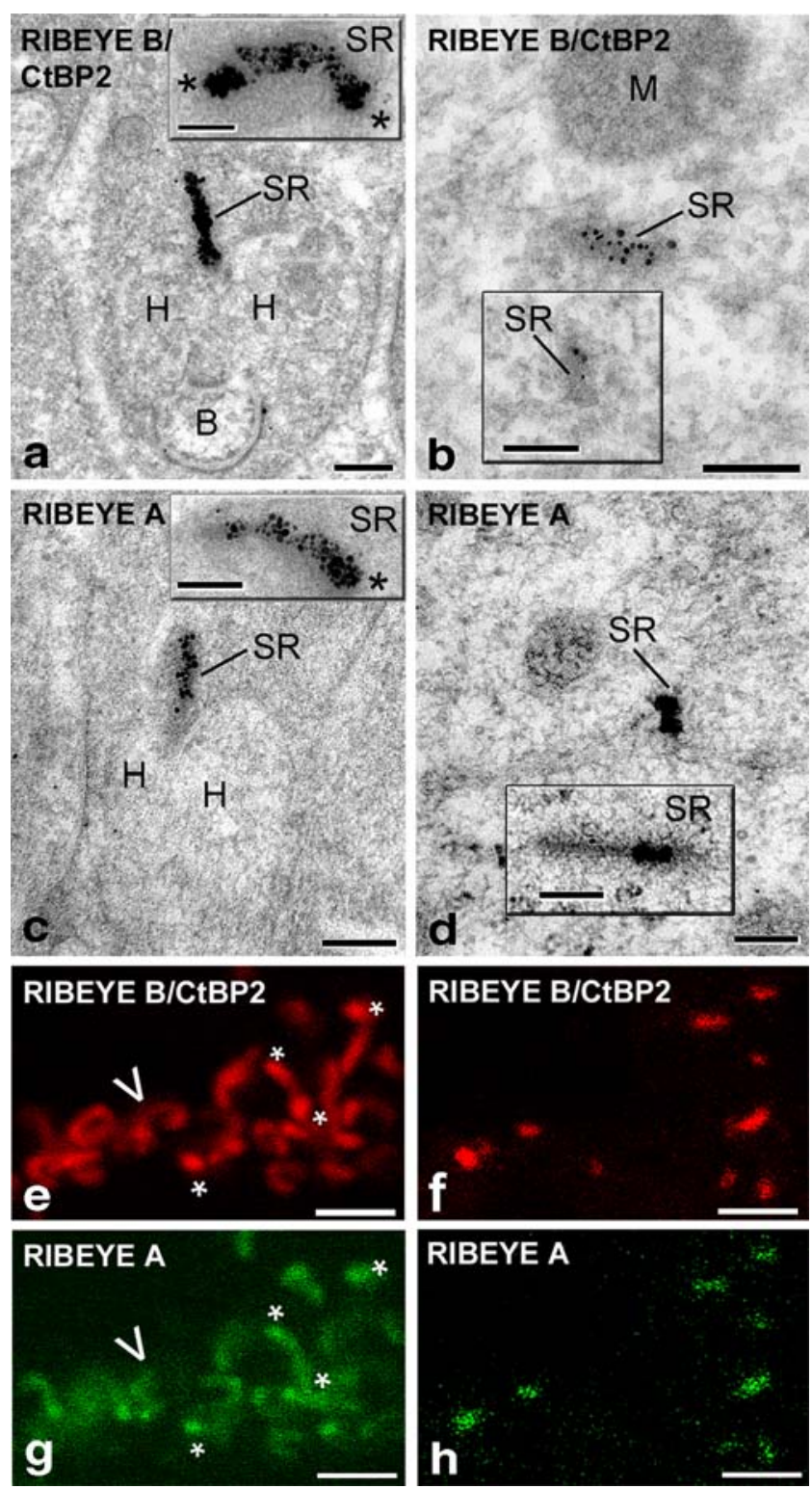

Fig. 2 RIBEYE as a marker for synaptic ribbons $(S R \mathrm{~s})$. The postembedding immunogold electron micrographs (a-d) show that SRs are strongly labeled with gold particles (silver-enhanced staining) for the RIBEYE B-domain (a, b) and A-domain (c, d) in rod photoreceptor terminals $(\mathbf{a}, \mathbf{c})$ and pinealocytes $(\mathbf{b}, \mathbf{d})$. Insets in $\mathbf{a}, \mathbf{c}$ : Typical horseshoe-like shape of a sagittally sectioned SR in rod cell endings. Insets in $\mathbf{b}, \mathbf{d}$ : Additional pinealocyte SRs. The confocal light micrographs (e-h) reveal SRs labeled with antibodies against the RIBEYE B-domain $(\mathbf{e}, \mathbf{f})$ and A-domain $(\mathbf{g}, \mathbf{h})$ in rod photoreceptor terminals $(\mathbf{e}, \mathbf{g})$ and pinealocytes $(\mathbf{f}, \mathbf{h})$. Both electron microscopy and confocal light microscopy demonstrate that most photoreceptor SRs have a horseshoe-like shape with increased RIBEYE staining at the free endings (asterisks in a, c, e, $\mathbf{g}$; arrowhead a sagittally sectioned SR), whereas pinealocyte SRs are generally punctate or rod-like and uniformly stained throughout their matrix. Tissue was obtained from rats kept under a 12:12 light/dark regime and killed $7 \mathrm{~h}$ after dark onset ( $B$ bipolar cell dendrite, $H$ horizontal cell process, $M$ mitochondrion). Bars $0.2 \mu \mathrm{m}$ (a-d), $2 \mu \mathrm{m}(\mathbf{e}-\mathbf{h})$
1999; Dick et al. 2001; tom Dieck et al. 2005) were associated with SRs in rat pinealocytes. To this end, RIBEYE and the CAZ proteins under consideration were studied by immunocytochemical co-localization. In the rat pineal gland, the antibodies against CtBP1, Bassoon, Piccolo, Munc13-1, and KIF3A produced a strong punctuate or rod-like staining associated with RIBEYE. CtBP1 was also demonstrable in pinealocyte nuclei. Proteins that completely co-localized with RIBEYE included CtBP1 (Fig. 3c,d), Bassoon (Fig. 4b), and Piccolo (Fig. 4d). Munc13-1 (Fig. 4f) was concentrated at one side of the RIBEYE-labeled SRs, giving rise to a few distinct blobs. KIF3A immunoreactivity (Fig. 4g) also appeared at one side of the SR only and, depending on the orientation of the $\mathrm{SR}$, formed a band or a single blob partly surrounded by RIBEYE immunoreactivity. RIM1, RIM2, and ERC/CAST staining was not concentrated at SRs but appeared in diffuse form in the cytoplasm of pinealocytes (not shown). RIM1 staining was weak, whereas RIM2 and ERC/CAST gave a strong staining reaction. Because of the diffuse staining, and as no day/night differences were observable, the latter CAZ proteins were excluded from further analysis.

\section{Diurnal changes of pinealocyte synaptic ribbons}

As SRs of pinealocytes are highly dynamic structures undergoing characteristic diurnal changes in size and/or number (Bhatnagar 1994; Vollrath and Spiwoks-Becker 2002), we next addressed the question of whether the demonstrated SR proteins underwent diurnal changes. To this end, we compared the immunoreactivities of the SRs between the day ( 7 hours after light onset) and night (7 hours after dark onset). Irrespective of whether antibodies against the A-domain or the B-domain of RIBEYE were used, the density of the immunoreactivity did not detectably differ between day (Fig. 3a) and night (Fig. 3b). At night, SRs increased in size (up to $1.5 \mu \mathrm{m}$; Figs. 3, 4) and changed their shapes to slightly curved, crescent, or horseshoe-like structures (see white box in Fig. 3b). CtBP1 co-localized with RIBEYE to a similar extent during the day and night (Fig. 3c,d). By contrast, the staining for Bassoon, Piccolo, and Munc13-1 and their colocalization with RIBEYE was weak during the day and strong at night (Fig. 4a-f). KIF3A revealed an inverse behavior with accumulation at RIBEYE sites during the day and weak staining at night (Fig. 4g,h).

By measuring the amount of transcripts and proteins, we further addressed the question of whether the daily changes of the SR-associated proteins were the result of de novo formation (Fig. 5). Whereas the key enzyme of melatonin formation in the pineal gland, arylalkylamine N-acetyltransferase (AA-NAT), revealed its well-established noctur- 


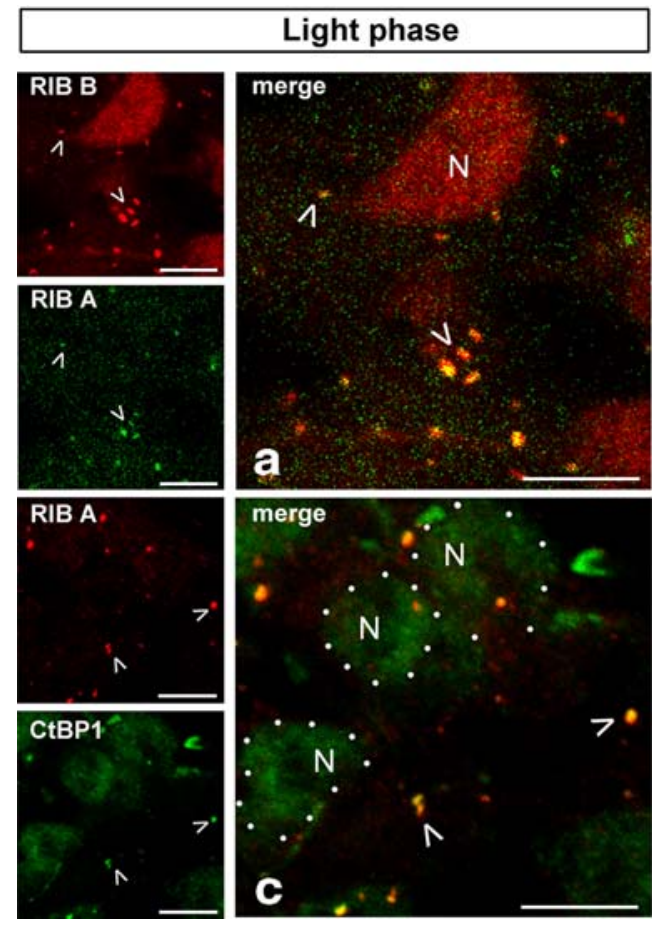

Fig. 3 Association of SRs with RIBEYE and CtBP1 in rat pinealocytes under light and dark conditions. a, b As seen in the merged image (merge) of the high power confocal laser-scanning images, RIBEYE-B-labeled ( $R I B B)$ SRs (red) completely co-localize (examples marked by arrowheads) with RIBEYE A (RIB A; green), irrespective of day (a) or night (b) conditions. At night, SRs are often larger and show a more irregular shape (e.g., see the long curved SR in

nal increase $(P<0.001$; Fig. $5 f)$, no statistically significant day/night differences occurred in the formation of mRNAs for RIBEYE $(P=0.95)$, Bassoon $(P=0.32)$, Piccolo $(P=0.67)$, Munc13-1 $(P=0.083)$, and KIF3A $(P=0.67$; Fig. 5a-e). As found for the the level of transcripts, the components of the ribbon complex were equally expressed at day and night at the protein level (Fig. $5 \mathrm{~g}$ ).

Pinealocyte ribbon complex under constant darkness and constant illumination

The pineal gland is under the control of the hypothalamic master oscillator, which is truly circadian, i.e., persists in oscillating even under constant darkness (for a review, see Hastings and Herzog 2004). To investigate whether the above-mentioned day/night differences in the SR-associated proteins were circadian in nature, rats kept for $48 \mathrm{~h}$ under constant darkness were studied. As illustrated in the example for Bassoon (Fig. 6a,b), all the day/night changes described above persisted, revealing an underlying circadian-clockdriven mechanism.

The suprachiasmatic nucleus controls the pineal gland primarily through the nocturnal release of noradrenaline from intrapineal sympathetic nerve fibers (Korf et al. 1998).

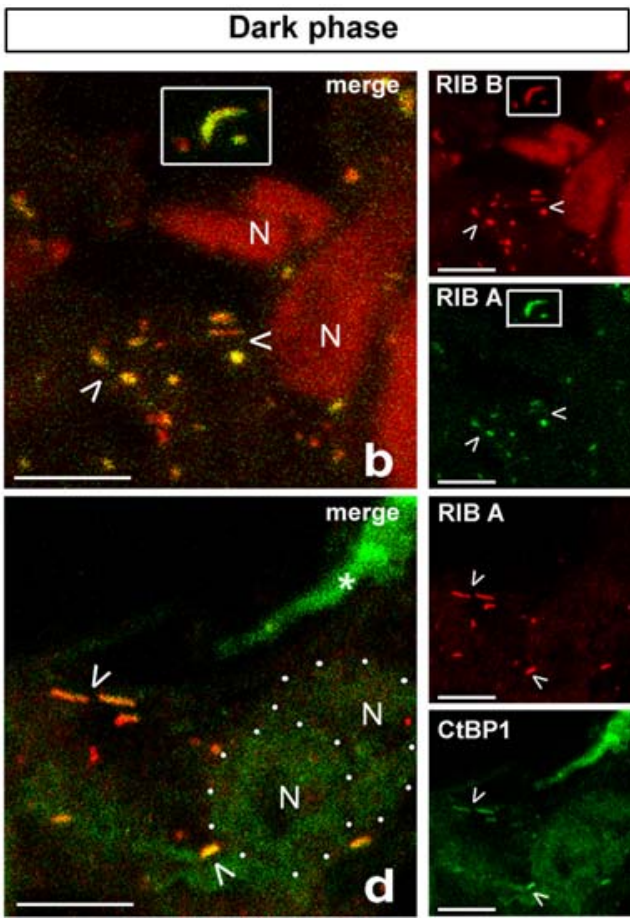

the white box in $\mathbf{b}$; compare also Fig. 4). c, d Double-labeling of RIBEYE A (red) and CtBP1 (green), a homolog of CtBP2, shows complete co-localization that does not vary between day (c) and night (d). Note that anti-RIBEYE B additionally labels nuclear CtBP2 $(N$ in a, b). The typical RIBEYE B/CtBP2 labeling of the SRs and nuclei $(N)$ is stronger compared with the CtBP1 labeling (nuclei are indicated by white dots in c, d). Asterisks Unidentified processes. Bars $5 \mu \mathrm{m}$

The significance of sympathetic innervation and adrenergic stimulation for the protein composition of the ribbon complex was investigated by using a treatment that blocked adrenergic stimulation of the pineal gland, i.e., exposure to constant light. Under constant light for $48 \mathrm{~h}$, the nocturnal staining intensity for Bassoon (Fig. 6c,d), Piccolo, and Munc13-1 decreased, coming close to the day-time staining intensity. Likewise, but with an opposite character, the nocturnal staining intensity for KIF3A increased to the daytime level.

\section{Discussion}

Pinealocyte synaptic ribbons contain key molecules characteristic for sensory cell synaptic ribbons

Despite preliminary observation of RIBEYE B immunoreactivity in rat pinealocytes (Schmitz et al. 2000), little is known about the molecular configuration of pinealocyte SRs. We have confirmed and corroborated the presence of RIBEYE in pineal SRs by applying antibodies against both the B-domain and the A-domain of RIBEYE in analyses by light and electron microscopy. The use of antibodies against 
Fig. 4 Diurnal changes in the protein composition of the pinealocyte ribbon complex. Confocal laser-scanning micrographs of sections of the rat pineal gland double-labeled for the synaptic ribbon $(S R)$ marker RIBEYE combined with Bassoon, Piccolo, Munc13-1, and KIF3A. Left Day-time (7 hours after light onset). Right Night (7 hours after dark onset). In the merged images of staining (merge), Bassoon (a versus b), Piccolo (c versus d), and Munc13-1 (e versus f) exhibit only weak labeling at day, but strong signals at night. In contrast, KIF3A (g versus $\mathbf{h}$ ) shows prominent staining during the day, whereas under dark conditions, only faint labeling is visible. Arrowheads in $\mathbf{a}, \mathbf{b}, \mathbf{d}, \mathbf{f}$, g Examples of double-labeling of SRs. Note that Bassoon (b) and Piccolo (d) are completely co-localized with RIBEYE in contrast to KIF3A, which is only partially co-localized with RIBEYE. Munc13-1 (f) is closely associated with the SRs, but the staining does not overlap completely (thin arrows). Noncolocalized regions appear red, whereas small overlapping parts appear yellow. Note also that, at night, SRs are larger with a more variable appearance (see also Fig. 3). In addition to SRs, the antibodies against Bassoon (asterisk in b) and KIF3A (asterisk in $\mathbf{g}$ ) stain some unidentified processes. Note the nuclei $(N)$ labeled with anti-RIBEYE B (RIB B). Bars $5 \mu \mathrm{m}$
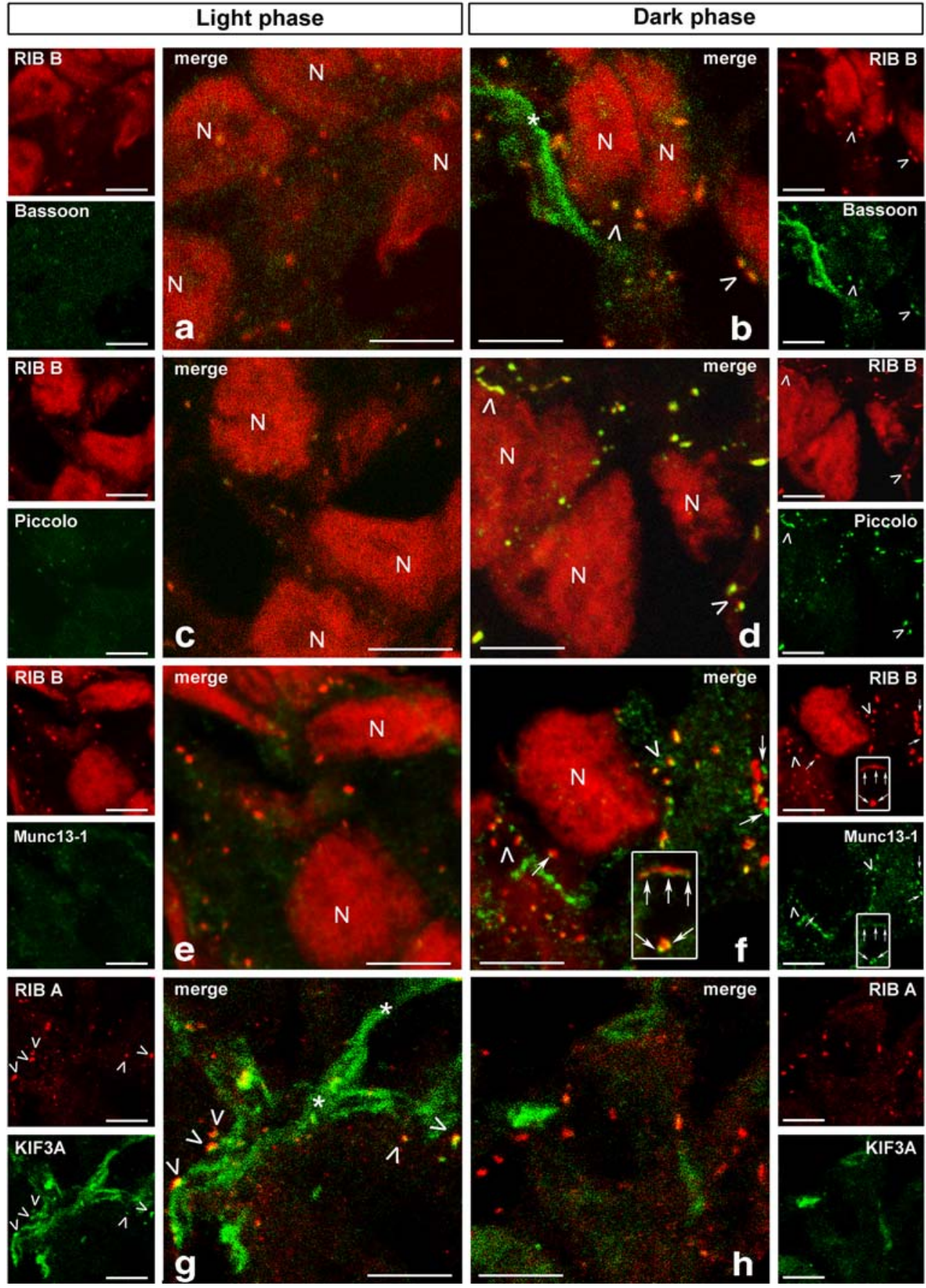

RIBEYE as molecular markers for pinealocyte SRs has enabled us to identify further SR-associated proteins by means of double-labeling experiments and confocal laser scanning microscopy. Our immunohistochemical studies clearly reveal that pineal SRs are associated with the proteins CtBP1, Bassoon, Piccolo, Munc13-1, and KIF3A. Each of these proteins is also abundant in the ribbon complex of photoreceptors (tom Dieck et al. 2005) and hair cells (Khimich et al. 2005). Therefore, the ribbon complex of pinealocytes resembles that of sensory cells. However, some differences have been noted.
The ribbon complex contains RIMs and ERC/CAST in photoreceptor terminals (tom Dieck et al. 2005; DeguchiTawarada et al. 2006) but not in pinealocytes (this study). In photoreceptor cells, ERC2/CAST1 might link the arciform density and Bassoon, both located at the base of the SR. In the pineal gland, typical arciform densities are lacking, although a similar structure is present (Jastrow and Racke 2007), and Bassoon seems to be evenly spread over the SR (this study). Thus, the differences in the presence of ERC2/CAST1 in the ribbon complex of photoreceptor cells and pinealocytes may reflect differences in the composition 


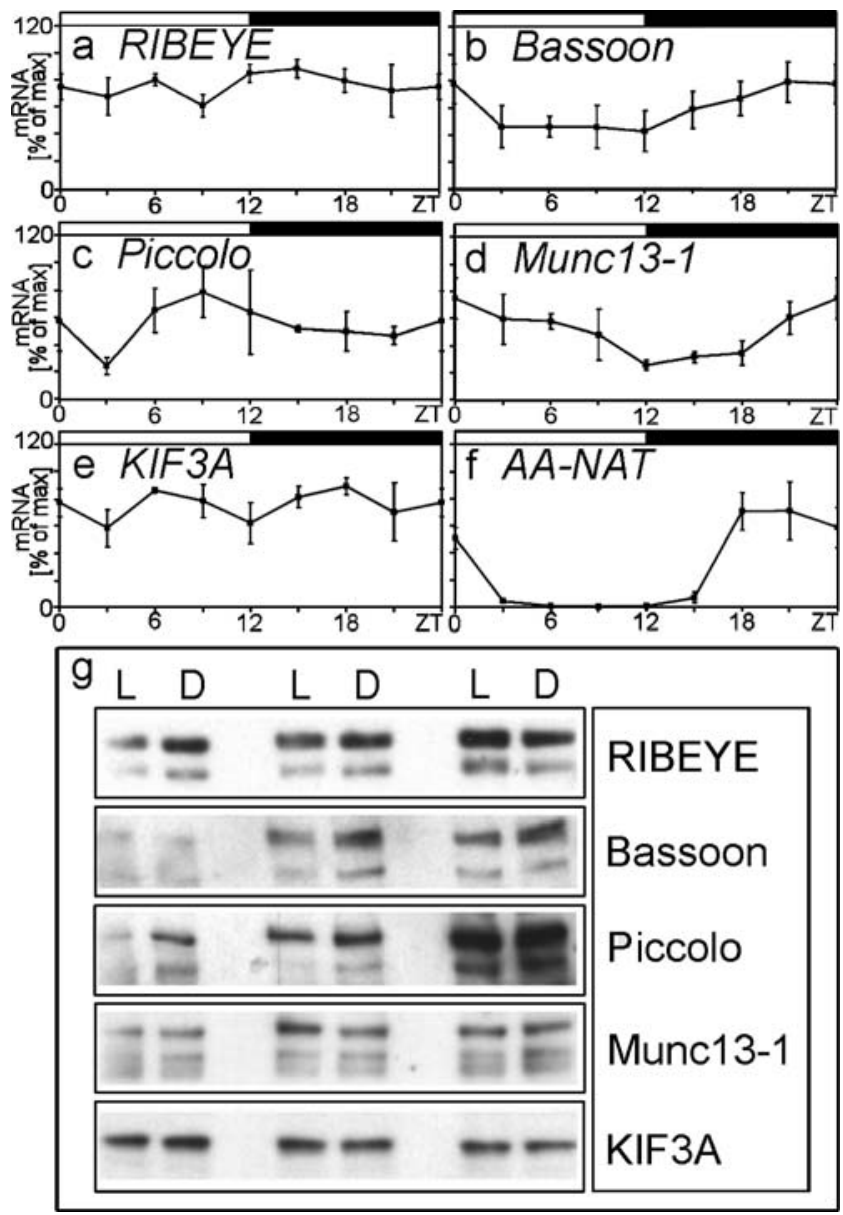

Fig. 5 Diurnal profiles in the amount of transcript (a-f) and of protein (g) of components of the ribbon complex in the rat pineal gland. $\mathbf{a}-\mathbf{f}$ Amount of transcript of RIBEYE (a), Bassoon (b), Piccolo (c), Munc13-1 (d), KIF3A (e), arylalkylamine N-acetyltransferase (AA$N A T ; \mathbf{f}$ ) as a function of light onset (solid bars dark period under the 12:12 light/dark regime, ZT Zeitgeber time). Significant 24-h oscillation is only found in the transcript amount of $A A-N A T$ (analyzed by one-way ANOVA: $P<0.001)$. Data represent a percentage of the maximal value of the light/dark cycle. Each value represents the mean $\pm \operatorname{SEM}(n=3$; each derived from two or three pooled pineal glands). g Western blot analysis showing immunoreactivities of protein components of the ribbon complex. Each lane represents an individual rat pineal gland 7 hours after light onset $(L, n=3)$ or after dark onset $(D, n=3)$. Lanes were loaded with $15 \mu \mathrm{g}$ of total protein. The proteins under investigation are equally expressed at day and night

of the link between the SR and the cell membrane. Similarities and differences are also evident with respect to the distribution of the proteins within the ribbon complex of photoreceptors and pinealocytes. Piccolo and CtBP1 are co-localized with RIBEYE along the whole length of SRs in photoreceptors (Dick et al. 2001; tom Dieck et al. 2005) and pinealocytes (this study), whereas Munc13-1 overlaps with RIBEYE only at a few places. The distribution of Bassoon and KIF3A varies between photoreceptor cells and pinealocytes. Bassoon has been reported to localize at the base of SRs in photoreceptor cells (Dick et al. 2001) and bipolar cells (Deguchi-Tawarada et al. 2006) but is colocalized with RIBEYE along the whole length of the SRs in pinealocytes (this study). Likewise, but with an opposite character, KIF3A completely co-localizes with RIBEYE in photoreceptor cells (tom Dieck et al. 2005) but only partially overlaps with RIBEYE in pinealocytes (this study). The observed different localization of active zone proteins in photoreceptors and pinealocytes may reflect a different localization of the anchor between the SR and the $\mathrm{CAZ}$ and of the machinery responsible for vesicle transport toward the SR, respectively.

Dynamic changes of pinealocyte SRs and their associated proteins

The present confocal light-microscopic investigation has revealed that the SRs of rat pinealocytes are larger at night than at day, confirming earlier observations from electron-microscopic analyses showing a nocturnal increase in size $(20 \%-30 \%$; Jastrow et al. 1997) and SR number (Kurumado and Mori 1977; Jastrow et al. 1997). We have also demonstrated day/night changes in shape. During the day, pinealocyte SRs typically appear as small puncta or rodlike structures, whereas at night, they are often slightly curved. Interestingly, the SR-associated CAZ proteins also exhibit day/night differences. Munc13-1 and the scaffolding proteins Bassoon and Piccolo co-localize with RIBEYE to a greater extent at night. In contrast, the motor protein KIF3A co-clusters with RIBEYE to a greater extent during the day. However, the amount of transcripts and proteins of Bassoon, Piccolo, Munc13-1, and KIF3A do not detectably change over the 24-h light/dark cycle. Therefore, the observed daily changes in the immunoreactivity of the ribbon-associated proteins might result from intracellular protein trafficking/ translocation. In photoreceptor cells, translocations of signaling molecules participate in long-term adaptation (Sokolov et al. 2002; Strissel et al. 2006). Bidirectional movements of arrestin, transducin, and recoverin between the compartments of the inner segment and the outer segment of photoreceptor cells are dependent on environmental light conditions (Strissel and Arshavsky 2004; Strissel et al. 2005). Movements of SR components may also contribute to the physiological status of pineal SRs. Another possibility is that SR-associated proteins undergo post-translational modification (Gower and Tytell 1986; Wu and Lynch 2006), which accounts for the day/night changes of pineal melatonin synthesis in certain species (Schomerus and Korf 2005).

What regulates the presently described day/night changes of the CAZ proteins? When the experimental animals are kept under constant darkness, the rhythmic changes persist, showing that the rhythm is circadian in nature, driven by the circadian oscillator within the supra- 
Fig. 6 Confocal laser-scanning images showing the association of Bassoon with synaptic ribbons (SRs) during subjective day $($ left $, \mathbf{a}, \mathbf{c})$ and subjective night $(r i g h t, \mathbf{b}, \mathbf{d})$ under constant darkness $(D D)$ and constant light $(L L)$. Animals previously kept under a 12:12 light/dark regime (LD) were housed under constant darkness (top) or constant light (bottom), respectively, for two cycles. SRs were labeled with anti-RIBEYE B (RIB $B$; examples marked by arrowheads), which, additionally stained nuclei $(N)$. Under constant darkness, the daily change in the association of SRs with Bassoon observed under LD conditions persisted. Under constant light, the association of SRs with Bassoon was low at the subjective light phase and the subjective dark phase. Bars $5 \mu \mathrm{m}$
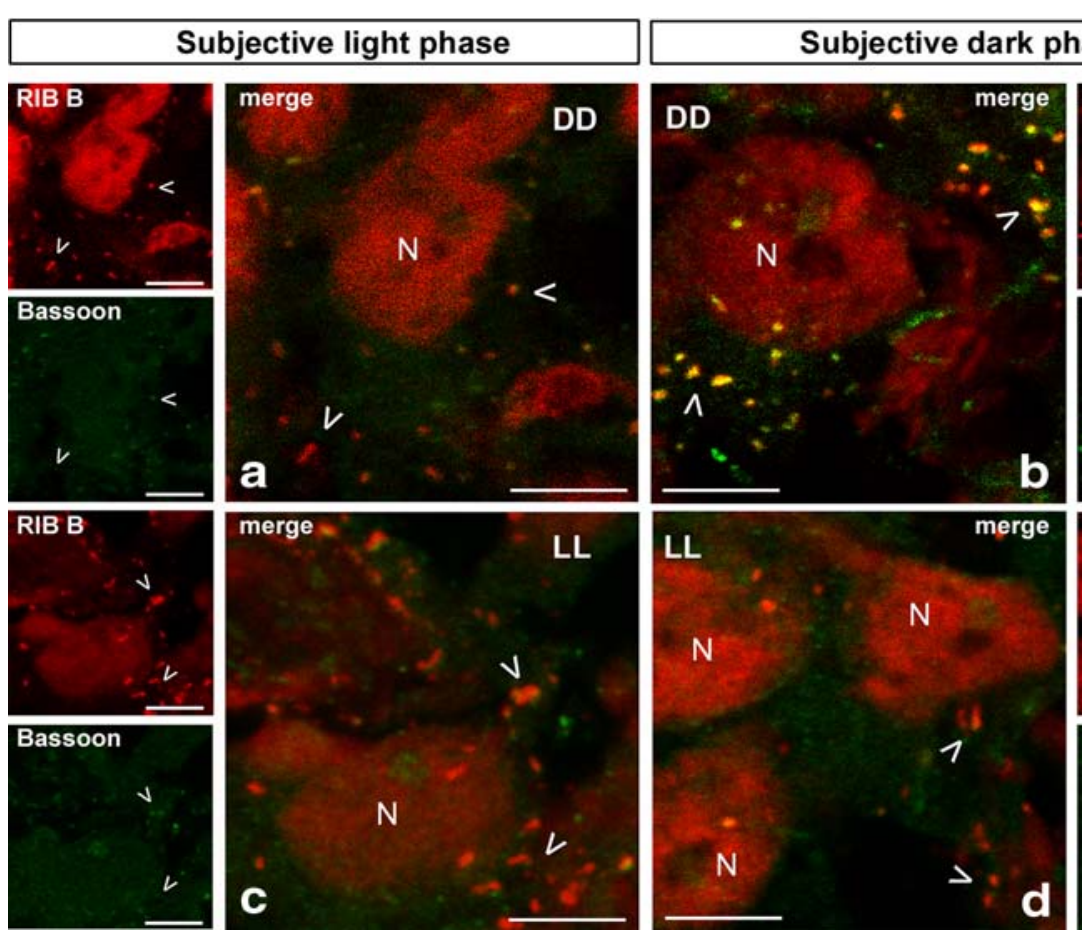

chiasmatic nucleus and, as is well known, mediated by the release of noradrenalin in the pineal gland in the dark phase (Hastings and Herzog 2004). As exposure to constant light abolishes the day/night rhythm of noradrenalin release (Korf et al. 1998), the abolishment of the day/night rhythm of the CAZ proteins is thus unsurprising.

\section{Pinealocyte SRs function in transmitter release}

Remarkably, the pineal gland of lower vertebrates is a mainly photoreceptive organ, whereas the neuroendocrine pinealocytes of mammals show a high degree of secretory activity and lack direct photosensitivity (Vollrath 1981; Oksche et al. 1987). Although mammalian pinealocytes obviously display more neuron-like structural and functional features than other neuroendocrine cells (Vollrath and Schröder 1987; Redecker 1999; Moriyama et al. 2000), the synaptic function of pineal SRs, as shown for SRs in sensory organs, has yet to be established.

This study shows that pinealocyte ribbon complexes are composed of proteins that appear to play important roles in the ribbon synapses of sensory cells. Munc13-1 is essential for priming synaptic vesicles to a fusion-competent state (Betz et al. 2001) and appears to potentiate neurotransmitter release (Rosenmund et al. 2002). CtBP1, a homolog of the RIBEYE-B-domain, is required for dynamin-independent membrane fission (Bonazzi et al. 2005), and the scaffolding proteins Bassoon and Piccolo participate in the assembly and spatial organisation of the active zone (Richter et al. 1999; Dick et al. 2001; Shapira et al. 2003). Therefore, the presence of these proteins in the ribbon complex suggests that pinealocyte SRs function in transmitter release and point-to-point signaling. This concept is supported by the occasional presence of specializations resembling pre- and postsynaptic densities, viz., coated pits and coated vesicles near SRs (McNulty and Fox 1992). Like SRs in the ribbon synapses of the retina (Yang 2004) and inner ear (Furness and Lawton 2003), pinealocyte SRs may function in glutamate release. Clear subcellular evidence exists that, in rat pinealocytes, the strongest glutamate labeling is present over SRs (McNulty et al. 1992) and that a sizable glutamate pool is present in the so-called synaptic-like microvesicles that accumulate in terminal swellings of pinealocyte processes where SRs also occur (Redecker 1999).

Since the secretory (for a review, see Korf et al. 1998) and electrical activity (Reuss and Vollrath 1984) of the pineal is higher at night than day, the prominent day/night changes of the SR-associated proteins demonstrated in the present study support the concept that pineal SRs are of functional significance. One of the proteins that is more strongly associated with pineal SRs at night than at day is Bassoon. In the retina, Bassoon is a well-known anchor of SRs to the presynaptic membrane/arciform density compartment (tom Dieck et al. 2005). Assuming that, in the pineal gland, Bassoon has a similar function as in the retina, the present findings indicate that, in the pineal gland, SRs are more tightly anchored to the plasma membrane at night than at day. In photoreceptor cells (Dick et al. 2003; tom Dieck et al. 2005) and hair cells (Khimich et al. 2005), 
Bassoon is a requirement for normal transmitter release. Therefore, in pinealocytes, the abundance of Bassoon in the ribbon complex at night may be indicative of enhanced nocturnal transmitter release. In photoreceptor cells of Bassoon mutant mice, SRs change their typical wild-type horseshoe-like shape to small oval immunoreactive puncta (tom Dieck et al. 2005). Therefore, another relevant function of Bassoon could be the shaping of SRs. We have shown that, during the day, when Bassoon immunoreactivity is low, SRs appear as small puncta or rod-like structures. In contrast, an increase in size and changes in shape of SRs have been observed in the dark phase, when Bassoon is concentrated at the SRs. This suggests that daily changes in the presence of Bassoon induce a daily rhythm in the size and shape of SRs. Piccolo, another CAZ protein associated with pineal SRs, shows stronger staining at night than during the day. Considering the role of Piccolo in the assembly and maintenance of the active zone (Shapira et al. 2003; Dresbach et al. 2006), the nocturnal abundance of Piccolo suggests a higher spatial organization of the plasma membrane close to the SR at night and, hence, supports the concept that SRs are in their active state at night. Enhanced vesicle release at night is also suggested by the presently observed increased association of Munc13-1 with ribbon material in the dark phase. Munc13-1 is a diacylglycerol receptor that is absolutely required for synaptic vesicle priming (Becherer and Rettig 2006). Its importance for exocytosis is underlined by the observation that Munc13-1deficient mice have reduced insulin secretion in pancreatic $\beta$-cells (Kwan et al. 2006).

KIF3A shows the opposite behavior. In photoreceptor cells, KIF3A is apparently associated with the ribbon matrix and synaptic vesicles (Muresan et al. 1999). As a component of the anterograde motor protein kinesin II, KIF3A might transport vesicle precursors from the Golgi complex toward the ribbon. Thus, the increase in KIF3A immunoreactivity in the light phase could be indicative of enhanced vesicle transport toward the ribbon or of the transport of a component of the ribbon matrix itself, further suggesting the incipient assembly or reconstruction of the ribbon matrix during the light phase.

\section{Concluding remarks}

The present results indicate that rat pinealocytes possess a protein complex that resembles the CAZ of ribbon synapses and whose dynamics are under circadian/adrenergic regulation. In rat pinealocytes, adrenergic signaling has been intensively investigated (for a review, see Gupta et al. 2005). Therefore, this study may provide a suitable basis for investigating the intracellular regulation of active zones.
Acknowledgements The authors thank Ilse von Graevenitz, Ursula Göringer-Struwe, and Lubin Belkovi for their excellent technical assistance, and Bettina Heerlein for secretarial help. Some of the data in this study form part of the doctoral thesis presented by Christian Maus at the Johannes Gutenberg University, Mainz, Germany.

\section{References}

Becherer U, Rettig J (2006) Vesicle pools, docking, priming and release. Cell Tissue Res 326:393-407

Betz A, Thakur P, Junge HJ, Ashery U, Rhee JS, Scheuss V, Rosenmund C, Rettig J, Brose N (2001) Functional interaction of the active zone proteins Munc13-1 and RIM1 in synaptic vesicle priming. Neuron 30:183-196

Bhatnagar KP (1994) Synaptic ribbons of the mammalian pineal gland: enigmatic organelles of poorly understood function. Adv Struct Biol 3:47-94

Bonazzi M, Spanò S, Turacchio G, Cericola C, Valente C, Colanzi A, Kweon HS, Hsu VW, Polishchuck EV, Polishchuck RS, Sallese M, Pulvirenti T, Corda D, Luini A (2005) CtBP3/BARS drives membrane fission in dynamin-independent transport pathways. Nat Cell Biol 7:570-580

Danscher G (1981) Histochemical demonstration of heavy metals. A revised version of the sulphide silver method suitable for both light and electron microscopy. Histochemistry 71:1-16

Deguchi-Tawarada M, Inoue E, Takao-Rikitsu E, Inoue M, Kitajima I, Ohtsuka T, Takai Y (2006) Active zone protein CAST is a component of conventional and ribbon synapses in mouse retina. J Comp Neurol 495:480-496

Dick O, Hack I, Altrock WD, Garner CC, Gundelfinger ED, Brandstätter JH (2001) Localization of the presynaptic cytomatrix protein Piccolo at ribbon and conventional synapses in the rat retina: comparison with Bassoon. J Comp Neurol 439:224-234

Dick O, Dieck S tom, Altrock WD, Ammermüller J, Weiler R, Garner CC, Gundelfinger ED, Brandstätter JH (2003) The presynaptic active zone protein Bassoon is essential for photoreceptor ribbon synapse formation in the retina. Neuron 37:775-786

Dieck S tom, Brandstätter JH (2006) Ribbon synapses of the retina. Cell Tissue Res 326:339-346

Dieck S tom, Sanmartí-Vila L, Langnaese K, Richter K, Kindler S, Soyke A, Wex H, Smalla KH, Kämpf U, Fränzer JT, Stumm M, Garner CC, Gundelfinger ED (1998) Bassoon, a novel zincfinger $\mathrm{CAG} /$ glutamine-repeat protein selectively localized at the active zone of presynaptic nerve terminals. J Cell Biol 142:499509

Dieck S tom, Altrock WD, Kessels MM, Qualmann B, Regus H, Brauner D, Fejtová A, Bracko O, Gundelfinger ED, Brandstätter JH (2005) Molecular dissection of the photoreceptor ribbon synapse: physical interaction of Bassoon and RIBEYE is essential for the assembly of the ribbon complex. J Cell Biol 168:825-836

Dresbach T, Qualmann B, Kessels MM, Garner CC, Gundelfinger ED (2001) The presynaptic cytomatrix of brain synapses. Cell Mol Life Sci 58:94-116

Dresbach T, Torres V, Wittenmayer N, Altrock WD, Zamorano P, Zuschratter W, Nawrotzki R, Ziv NE, Garner CC, Gundelfinger ED (2006) Assembly of active zone precursor vesicles: obligatory trafficking of presynaptic cytomatrix proteins Bassoon and Piccolo via a trans-Golgi compartment. J Biol Chem 281:6038-6047

Furness DN, Lawton DM (2003) Comparative distribution of glutamate transporters and receptors in relation to afferent innervation density in the mammalian cochlea. J Neurosci 23:11296-11304 
Gower DJ, Tytell M (1986) Protein modification by RNA-dependent posttranslational aminoacylation in synaptoplasm. J Neurochem 47:389-395

Gupta BBP, Spessert R, Vollrath L (2005) Molecular components and mechanism of adrenergic signal transduction in mammalian pineal gland: regulation of melatonin synthesis. Indian J Exp Biol 43:115-149

Hastings MH, Herzog ED (2004) Clock genes, oscillators, and cellular networks in the suprachiasmatic nuclei. J Biol Rhythms 19:400 413

Jastrow H, Mach MA von, Vollrath L (1997) The shape of synaptic ribbons in the rat pineal gland. Cell Tissue Res 287:255-261

Jastrow H, Racke J (2007) Analysis of synaptic bodies in the SpragueDawley rat pineal gland under extreme photoperiods. Micron 38:237-251

Khimich D, Nouvian R, Pujol R, Dieck S tom, Egner A, Gundelfinger ED, Moser T (2005) Hair cell synaptic ribbons are essential for synchronous auditory signalling. Nature 434:889-894

Korf HW, Schomerus C, Stehle JH (1998) The pineal organ, its hormone melatonin, and the photoneuroendocrine system. Adv Anat Embryol Cell Biol 146:1-100

Kurumado K, Mori W (1977) A morphological study of the circadian cycle of the pineal gland of the rat. Cell Tissue Res 182:565-568

Kwan EP, Xie L, Sheu L, Nolan CJ, Prentki M, Betz A, Brose N, Gaisano HY (2006) Munc13-1 deficiency reduces insulin secretion and causes abnormal glucose tolerance. Diabetes 55:1421-1429

Lenzi D, Gersdorff H von (2001) Structure suggests function: the case for synaptic ribbons as exocytotic nanomachines. Bioessays $23: 831-840$

McNulty JA, Fox LM (1992) Pinealocyte synaptic ribbons and neuroendocrine function. Microsc Res Tech 21:175-187

McNulty JA, Kus L, Ottersen OP (1992) Immunocytochemical and circadian biochemical analysis of neuroactive amino acids in the pineal gland of the rat: effect of superior cervical ganglionectomy. Cell Tissue Res 269:515-523

Morgans CW (2000) Neurotransmitter release at ribbon synapses in the retina. Immunol Cell Biol 78:442-446

Moriyama Y, Hayashi M, Yamada $\mathrm{H}$, Yatsushiro S, Ishio $\mathrm{S}$, Yamamoto A (2000) Synaptic-like microvesicles, synaptic vesicle counterparts in endocrine cells, are involved in a novel regulatory mechamism for the synthesis and secretion of hormones. J Exp Biol 203:117-125

Muresan V, Lyass A, Schnapp BJ (1999) The kinesin motor KIF3A is a component of the presynaptic ribbon in vertebrate photoreceptors. J Neurosci 19:1027-1037

Nouvian R, Beutner D, Parsons TD, Moser T (2006) Structure and function of the hair cell ribbon synapse. J Membr Biol 209:153165

Oksche A, Korf HW, Rodriguez EM (1987) Pinealocytes as photoneuroendocrine units of neuronal origin: concepts and evidence. Adv Pineal Res 2:1-18

Rao-Mirotznik R, Harkins AB, Buchsbaum G, Sterling P (1995) Mammalian rod terminal architecture of a binary synapse. Neuron 14:561-569

Redecker P (1999) Synaptic-like microvesicles in mammalian pinealocytes. Int Rev Cytol 191:201-255

Reuss S, Vollrath L (1984) Electrophysiological properties of rat pinealocytes: evidence for circadian and ultradian rhythms. Exp Brain Res 55:455-461
Richter K, Langnaese K, Kreutz MR, Olias G, Zhai R, Scheich H, Garner CC, Gundelfinger ED (1999) Presynaptic cytomatrix protein bassoon is localized at both excitatory and inhibitory synapses of rat brain. J Comp Neurol 408:437-448

Rosenmund C, Sigler A, Augustin I, Reim K, Brose N, Rhee JS (2002) Differential control of vesicle priming and short-term plasticity by Munc13 isoforms. Neuron 33:411-424

Schmitz F, Königstorfer A, Südhof TC (2000) RIBEYE, a component of synaptic ribbons: a protein's journey through evolution provides insight into synaptic ribbon function. Neuron 28:857-872

Schomerus C, Korf HW (2005) Mechanisms regulating melatonin synthesis in the mammalian pineal gland. Ann N Y Acad Sci 1057:372-383

Shapira M, Zhai RG, Dresbach T, Bresler T, Torres VI, Gundelfinger ED, Ziv NE, Garner CC (2003) Unitary assembly of presynaptic active zones from Piccolo-Bassoon transport vesicles. Neuron $38: 237-252$

Sokolov M, Lyubarsky AL, Strissel KJ, Savchenko AB, Govardovskii VI, Pugh EN Jr, Arshavsky VY (2002) Massive light-driven translocation of transducin between the two major compartments of rod cells: a novel mechanism of light adaptation. Neuron 34:95-106

Spiwoks-Becker I, Glas M, Lasarzik I, Vollrath L (2004) Mouse photoreceptor synaptic ribbons lose and regain material in response to illumination changes. Eur J Neurosci 19:1559-1571

Sterling P, Matthews G (2005) Structure and function of ribbon synapses. Trends Neurosci 28:20-29

Strissel KJ, Arshavsky VY (2004) Myosin III illuminates the mechanism of arrestin translocation. Neuron 43:2-4

Strissel KJ, Lishko PV, Trieu LH, Kennedy MJ, Hurley JB, Arshavsky VY (2005) Recoverin undergoes light-dependent intracellular translocation in rod photoreceptors. J Biol Chem 280:29250 29255

Strissel KJ, Sokolov M, Trieu LH, Arshavsky VY (2006) Arrestin translocation is induced at a critical threshold of visual signalling and is superstoichiometric to bleached rhodopsin. J Neurosci 26:1146-1153

Vollrath L (1973) Synaptic ribbons of a mammalian pineal gland: circadian changes. Z Zellforsch 145:171-183

Vollrath L (1981) The pineal organ. In: Oksche A, Vollrath L (eds) Handbuch der Mikroskopischen Anatomie des Menschen, Vol VI/7. Springer, Berlin Heidelberg New York, pp 1-665

Vollrath L, Schröder H (1987) Neuronal properties of mammalian pinealocytes. In: Trentini GP, DeGaetani C, Pévet P (eds) Serono: fundamentals and clinics in pineal research. Symposia publications, vol 44. Raven, New York, pp 13-23

Vollrath L, Spiwoks-Becker I (1996) Plasticity of retinal ribbon synapses. Microsc Res Tech 35:472-487

Vollrath L, Spiwoks-Becker I (2002) Pineal synaptic ribbons: new light from the retina. In: Haldar C, Singaravel M, Maitra SK (eds) Treatise on pineal gland and melatonin, vol 3. Oxford \& IBH, New Delhi, pp 51-63

Wolfrum U, Schmitt A (2000) Rhodopsin transport in the membrane of the connecting cilium of mammalian photoreceptor cells. Cell Motil Cytoskeleton 46:95-107

Wu HY, Lynch DR (2006) Calpain and synaptic function. Mol Neurobiol 33:215-236

Yang XL (2004) Characterization of receptors for glutamate and GABA in retinal neurons. Prog Neurobiol 73:127-150

Zhai RG, Bellen HJ (2004) The architecture of the active zone in the presynaptic nerve terminal. Physiol Rev 19:262-270 